\title{
The rapid generation of isothiocyanates in flow
}

\author{
Marcus Baumann and lan R. Baxendale*
}

Open Access

\author{
Full Research Paper \\ Address: \\ Department of Chemistry, University of Durham, South Road, Durham \\ DH1 3LE, United Kingdom \\ Email: \\ lan R. Baxendale* - i.r.baxendale@durham.ac.uk \\ * Corresponding author \\ Keywords: \\ chloroxime; dipolar cycloaddition; flow chemistry; flow synthesis; \\ immobilised reagents; isothiocyanate; nitrile oxide
}

Beilstein J. Org. Chem. 2013, 9, 1613-1619.

doi:10.3762/bjoc.9.184

Received: 20 June 2013

Accepted: 23 July 2013

Published: 08 August 2013

This article is part of the Thematic Series "Chemistry in flow systems III".

Guest Editor: A. Kirschning

(c) 2013 Baumann and Baxendale; licensee Beilstein-Institut. License and terms: see end of document.

\begin{abstract}
Isothiocyanates are versatile starting materials for a wide range of chemical reactions. However, their high nucleophilic susceptibility means they are best prepared and used immediately. We report here on a flow platform for the fast and efficient formation of isothiocyanates by the direct conversion of easily prepared chloroximes. To expedite this chemistry a flow insert cartridge containing two immobilised reagents is used to affect the chemical transformation which typically eliminates the requirements for any conventional work-up or purification of the reaction stream.
\end{abstract}

\section{Introduction}

Flow based chemical synthesis is playing an increasingly pivotal role within the chemical sciences as it facilitates a more versatile and responsive workflow. It encompasses many aspects of synthesis from the rapid and on-demand preparation of important building blocks to the development of multi-step sequences leading to advanced chemical structures and more direct scaling of bulk producing reactions [1-10]. Consequently, the chemical literature is growing at a precipitous rate with numerous examples of key chemical transformations having been further optimised or improved upon when conducted within a pseudo-/continuous flow process $[11,12]$. From a synthesis perspective the majority of these endeavours have been directed at enhancing specific reaction safety profiles, identifying new reaction sequences or generating improvements to well-known yet cumbersome transformations [13-16]. Indeed, flow chemistry is moving from an academic curiosity to become a common tool in many synthesis laboratories paralleling the emergence and adoption of another enabling technology, the microwave reactor [17].

An area which has benefited significantly from the many recent developments in our understanding of flow chemistry is the synthesis of reactive precursors and handling of sensitive intermediates [18-23]. However, despite the breadth of chemistries already explored there are certain functional transformations notably absent, one particular class of important building blocks which has received less attention are isothiocyanates. These species are widely utilised as valuable starting materials for many thiourea-based organocatalysts [24-26], numerous heterocyclic entities [27-29] as well as important entry points towards 
other key functional groups such as isocyanides [30,31], guanidines [32,33] and thiosemicarbazides [34]. Due to the limited commercial availability of diversely functionalised isothiocyanates chemists normally pursue a de novo synthesis, which most commonly involves the condensation of an amine with thiophosgene or carbon disulfide [35,36], both reagents causing safety concerns due to the formation of toxic, malodorous and/ or extremely corrosive byproducts (Scheme 1a). An underutilised alternative sequence is the 1,3-dipolar cycloaddition reaction between a nitrile oxide and a thiourea compound which initially generates an unstable 1,4,2-oxathiazoline intermediate that readily rearranges into urea and eliminates the desired isothiocyanate product $[37,38]$ (Scheme 1b).

\section{a) conventional condensation strategy:}

$$
\mathrm{R}^{-\mathrm{NH}_{2} \stackrel{\mathrm{CS}_{2} \text { or } \mathrm{SCCl}_{2}}{\longrightarrow}} \mathrm{R}_{\mathrm{X}=\mathrm{SH}, \mathrm{Cl}}^{-\mathrm{N}} \prod_{\mathrm{S}}^{\mathrm{H}} \underset{-\mathrm{HX}}{\mathrm{X}} \mathrm{R}^{-\mathrm{N}}=\mathrm{C} \text { S }
$$

b) 1,3-dipolar cycloaddition route:

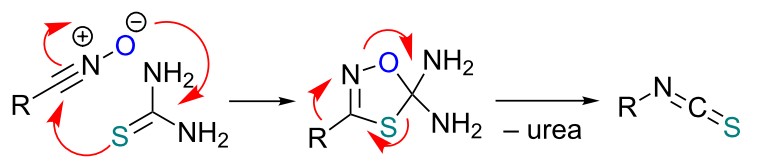

Scheme 1: Strategies towards isothiocyanates.

Whilst this approach appears on initial inspection to be very attractive it is somewhat hampered by the requirement to access the reactive nitrile oxide species, which once formed is prone to undergo fast dimerisation leading to furoxan byproducts (see Table 1) [39]. In fact this facile dimerisation reaction is regularly reported as troublesome in many reactions that progress through nitrile oxide intermediates. As a consequence a number of strategies to minimise this side reaction have been attempted. These include the use of highly diluted reaction mixtures, the use of large excesses of the corresponding dipolarophile partner, as well as the slow addition of reagents to create limiting concentrations of the active 1,3-dipole. Despite these efforts, the side reaction is still seen and there normally remains the requirement for time consuming purifications such as column chromatography in order to isolate pure products.

Immobilised reagents have shown great promise as enabling technologies when incorporated in flow reactors to aid in the processing, work-up and purification of reaction sequences [4044]. In addition they have been successfully utilised in order to render dipolar cycloaddition reactions involving azomethine ylides $[45,46]$ as well as nitrile oxides $[47,48]$ more practical for generating important heterocyclic scaffolds such as pyrrolidines, isoxazolines and their derivatives [49-52]. We therefore considered that it should be possible to develop a mild and practical flow-based process to form isothiocyanates from the corresponding reactive nitrile oxide intermediates.

Our strategy makes use of two immobilised reagents (a weak base and a functionalised thiourea) placed as a 1:1-mixture within a single glass reactor cartridge (Scheme 2). The immobilised base affects the in situ formation of the reactive nitrile oxide from the chloroxime which is immediately captured by the local tethered thiocarbonyl dipolarophile. Consequently, this approach significantly minimises the formation of the furoxan byproduct by creating a scenario of pseudo high dilution of the nitrile oxide whilst allowing a concurrent high local concentration of the dipolarophile. Additionally the immobilised supports act as excellent sequestering agents for trapping even the small quantities of polar impurities within the matrix thus allowing for the isolation of the desired isothiocyanate product in high purity after only simple solvent removal.

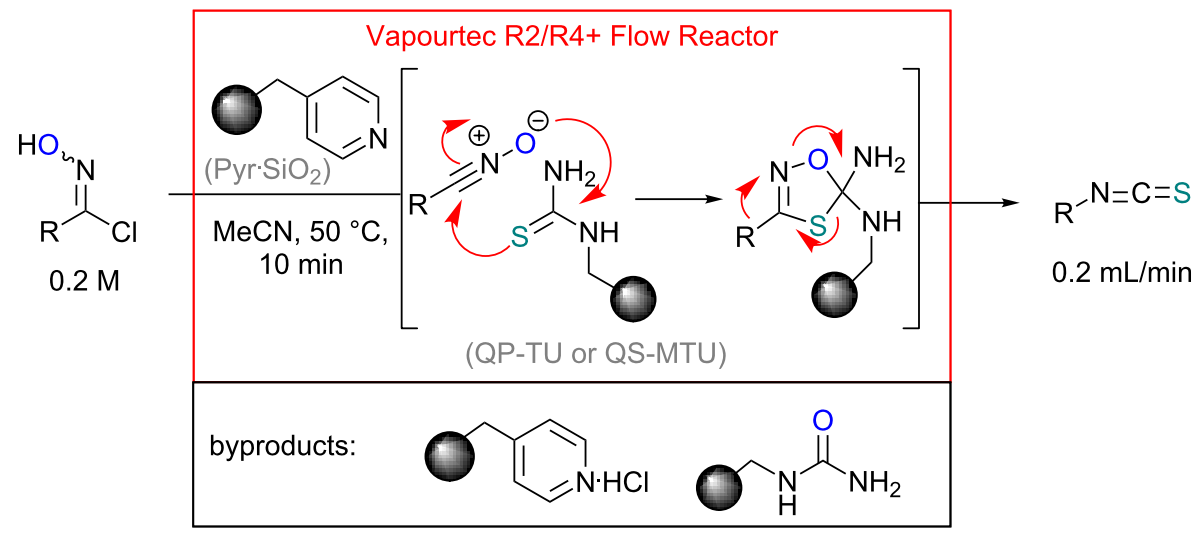




\section{Results and Discussion}

Initially a set of batch experiments was performed using (4-bromophenyl)chloroxime 1a as the substrate, which was efficiently prepared on gram scale from the corresponding benzaldehyde via oxime formation and subsequent NCS-mediated chlorination [53]. Screening different solvents (MeCN, acetone, EtOAc, $\mathrm{MeOH}$ and $\mathrm{PrOH}$ ) and immobilised thiourea species (QP-TU [54] and QS-MTU [55]) showed that the desired transformation can be effected with either immobilised thiourea source and furthermore tolerates a wide range of the solvents, with $\mathrm{MeCN}$ being identified as the best option. The choice of base was found to be of particular importance given that solution phase bases tested ( $\mathrm{NEt}_{3}$ or DBU even using slow addition) immediately generated substantial quantities of a white precipitate, which was later identified as the undesired furoxan byproduct (Table 1). In order to evaluate conditions to minimise this side reaction we studied several immobilised bases including QP-DMA (benzyldimethylamine resin) and $\mathrm{SiO}_{2}$-pyr. The latter allowed for the isolation of the desired isothiocyanate in high yield and with very little contamination by the furoxan byproduct.

We translated the outcome of these preliminary results into a flow protocol using a commercially available Vapourtec $\mathrm{R}$ series flow reactor [56] which was operated with $\mathrm{MeCN}$ as the system solvent. Stock solutions of the chloroxime starting materials were prepared in the same solvent $(0.25-0.5 \mathrm{M})$ and injected into a sample loop $(2-10 \mathrm{~mL}$ size). Both the solid supported base $\left(\mathrm{SiO}_{2}\right.$-pyr) and immobilised thiourea species (QP-TU or QS-MTU) were blended (by shaking), filled into an glass column (10 cm length, $6.6 \mathrm{~mm}$ i.d., 1:1 ratio, 1.2 equiv each species) and the column inserted into a glass heating jacket which was maintained at $50{ }^{\circ} \mathrm{C}$. The flow stream of the substrate was subsequently directed through the heated reactor column at a flow rate of $0.2 \mathrm{~mL} / \mathrm{min}$ equating to an average residence time of 10 minutes. After passing a 100 psi backpressure regulator the typically colourless reaction mixture was collected yielding the product after evaporation of the solvent. ${ }^{1} \mathrm{H}$ NMR experiments were used to determine the product composition and purity and pleasingly revealed complete conversion of the substrates into the desired isothiocyanate product in high yield and purity as summarised in Table 2 .

The reactions demonstrate a high tolerance for both electron poor and electron rich aromatic substrates (Table 2, entries 1-8) which all delivered the desired isothiocyanates reliably in high yield and purity. Furthermore, aliphatic chloroximes were found to work equally well, efficiently generating the corresponding isothiocyanate products again in high yields and purities (Table 2, entries 9-12). When using single diastereoisomers of $\alpha$-chiral chloroximes the desired isothiocyanate product was correspondingly isolated as a single isomer (by ${ }^{1} \mathrm{H}$ NMR) suggesting a concerted reaction pathway to be in operation. Importantly, more complex substrates (i.e. $N$-chloropyrrolidines, Table 2, entries 13-15) can be subjected to the reaction conditions in order to not only install the desired isothiocyanate functionality but through concomitant elimination affect the formation of a cyclic imine, which is very attractive as it allows subsequent diversification of these polyfunctionalised heterocyclic building blocks. Overall, this exemplifies how the presented methodology can enable the rapid construction of scaffolds with unprecedented substitution patterns, which hold great interest due to their potential as highly decorated entities.

The most noteworthy feature of this flow protocol is its efficiency and simplicity allowing the desired product to be isolated following only solvent removal. The incomplete recovery

Table 1: Screening of different bases for the formation and conversion of nitrile oxides in batch:<smiles>C/C(=N/O)c1ccc(Br)cc1</smiles>

$1 a$

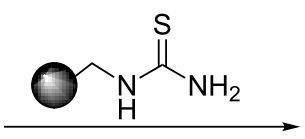

base, $\mathrm{MeCN}, \mathrm{rt}, 1 \mathrm{~h}$<smiles>CS(=O)(=O)c1ccc(Br)cc1</smiles>

$1 \mathrm{~b}$ desired isothiocyanate<smiles>[O-][n+]1onc(-c2ccc(Br)cc2)c1-c1ccc(Br)cc1</smiles>
$1 c$

furoxan byproduct

\begin{tabular}{llll}
\hline Entry & Base & Ratio isothiocyanate/furoxan & Comments \\
\hline 1 & $\mathrm{NEt}_{3}(0.2 \mathrm{M}$ in MeCN $)$ & $1: 1$ & dropwise addition of base \\
2 & $\mathrm{DBU}(0.2 \mathrm{M}$ in MeCN $)$ & $1: 1$ & dropwise addition of base \\
3 & $\mathrm{QP}^{-\mathrm{DMA}}$ & $2.2: 1$ & portionwise addition of base \\
4 & $\mathrm{SiO}_{2}-\mathrm{pyr}$ & $>4: 1$ & portionwise addition of base
\end{tabular}




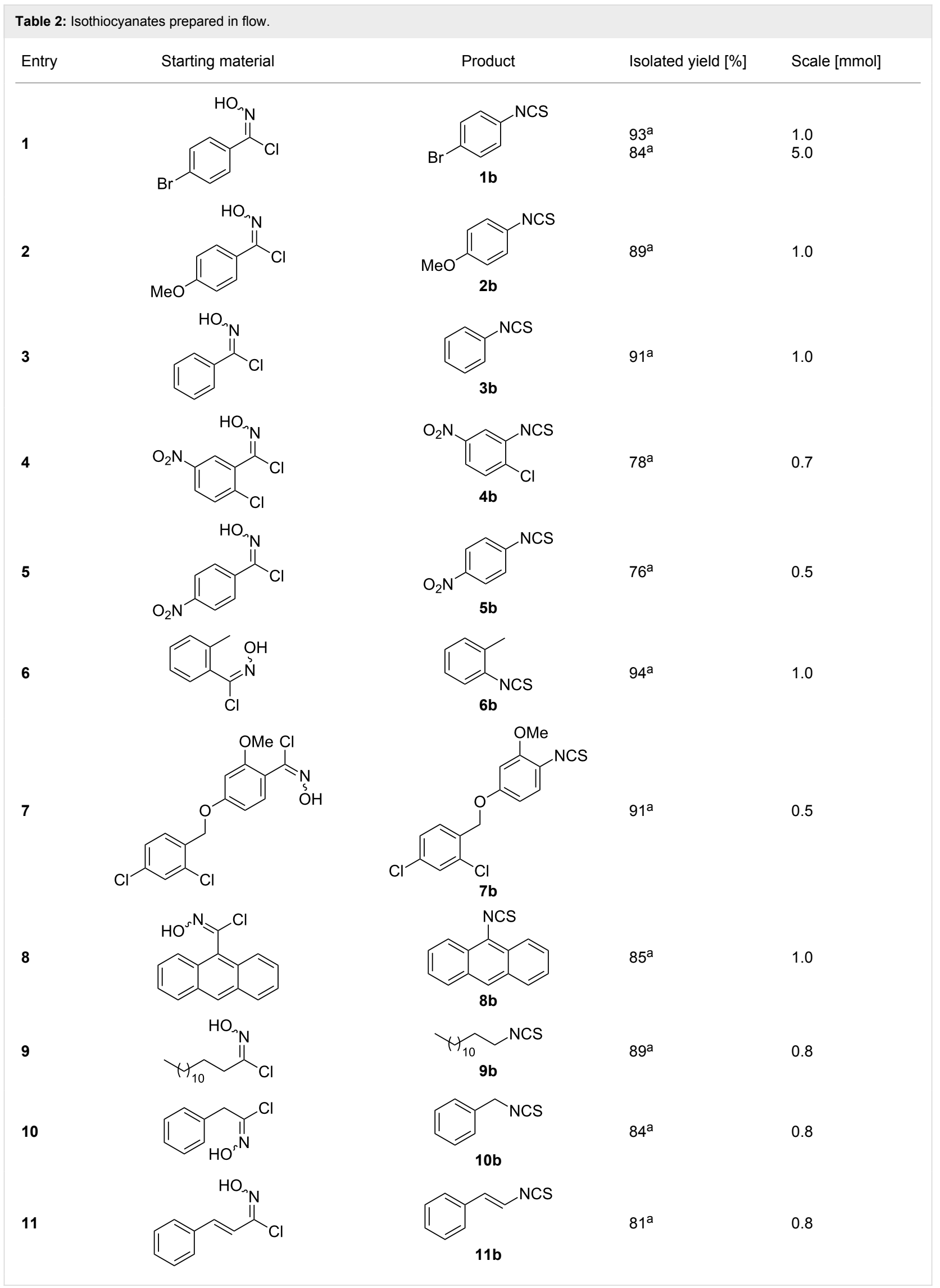


Table 2: Isothiocyanates prepared in flow. (continued)

12<smiles>CC(Cc1ccc2c(c1)OCO2)/C(Cl)=N\O</smiles>

13<smiles>CCOC(=O)C1C[C@@](C)(/C(Cl)=N\O)[C@H](c2ccc(Br)cc2)N1Cl</smiles>

14<smiles>CCOC1C[C@@](C)(/C(Cl)=N\O)C(c2cccc([N+](=O)[O-])c2)N1Cl</smiles>

15<smiles>CCOC(=O)C1C[C@@](C)(/C(Cl)=N\O)C(c2cccc([N+](=O)[O-])c2)N1Cl</smiles><smiles>CC(Cc1ccc2c(c1)OCO2)N=S</smiles><smiles>CCOC(=O)C1C[C@](C)(N(S)S(=O)(=O)c2ccc(Br)cc2)C(c2ccccc2)=N1</smiles>

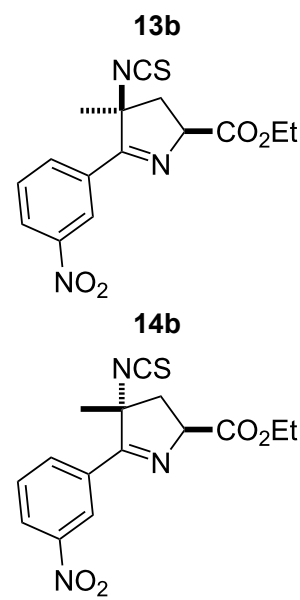

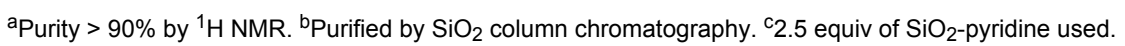

of material in these reactions can be accounted for by small amounts of the furoxan dimer which forms yet is trapped within the reactor column, thus evading its tedious removal via subsequent column chromatography. In addition our study demonstrates that thiourea - either immobilised on a polystyrene-type support (QP-TU) or on silica gel (QS-MTU) serves as an efficient source of a sulfur atom. Given the higher loading of QP-TU ( $5.5 \mathrm{mmol} / \mathrm{g})$ compared to QS-MTU $(\sim 1.5 \mathrm{mmol} / \mathrm{g})$ as well as its lower cost, QP-TU might be considered the more economical option, however, with the primary focus of this study being the small scale generation of valuable novel isothiocyanate products, this would only become relevant at larger scales $(>100 \mathrm{~g})$.

\section{Conclusion}

In conclusion, we have demonstrated an efficient and mild flow protocol for the synthesis of isothiocyanates from readily available chloroximes exploiting several immobilised reagents. This approach allows for the rapid access to various isothiocyanate building blocks avoiding time consuming purifications. Our study expands on the traditional use of immobilised thiourea species as simple metal scavengers and will likely lead to their further application as a convenient source of sulfur.

\section{Supporting Information}

\section{Supporting Information File 1}

Experimental part.

[http://www.beilstein-journals.org/bjoc/content/ supplementary/1860-5397-9-184-S1.pdf]

\section{Acknowledgements}

We would like to express our gratitude to the Royal Society for funding to support this research.

\section{References}

1. Wegner, J.; Ceylan, S.; Kirschning, A. Chem. Commun. 2011, 47, 4583-4592. doi:10.1039/c0cc05060a

2. Baumann, M.; Baxendale, I. R.; Ley, S. V. Mol. Diversity 2011, 15, 613-630. doi:10.1007/s11030-010-9282-1

3. Baxendale, I. R. J. Chem. Technol. Biotechnol. 2013, 88, 519-552. doi:10.1002/jctb.4012

4. Baxendale, I. R.; Brocken, L.; Mallia, C. J. Green Process Synth. 2013, 2, 211-230. doi:10.1515/gps-2013-0029

5. Wiles, C.; Watts, P. Green Chem. 2012, 14, 38-54. doi:10.1039/c1gc16022b 
6. Calabrese, G. S.; Pissavini, S. AIChE J. 2011, 57, 828-834. doi:10.1002/aic.12598

7. Hessel, V.; Cortese, B.; de Croon, M. H. J. M. Chem. Eng. Sci. 2011, 66, 1426-1428. doi:10.1016/j.ces.2010.08.018

8. Yoshida, J.-I.; Kim, H.; Nagaki, A. ChemSusChem 2011, 4, 331-340. doi:10.1002/cssc.201000271

9. Webster, A.; Greenman, J.; Haswell, S. J. J. Chem. Technol. Biotechnol. 2011, 86, 10-17. doi:10.1002/jctb.2482

10. Hartman, R. L.; McMullen, J. P.; Jensen, K. F. Angew. Chem., Int. Ed. 2011, 50, 7502-7519. doi:10.1002/anie.201004637

11. Yoshida, J. Flash Chemistry: Fast Organic Synthesis in Microsystems; John Wiley \& Sons: Chichester, UK, 2008.

12. Baxendale, I. R.; Griffiths-Jones, C. M.; Ley, S. V.; Tranmer, G. K. Chem.-Eur. J. 2006, 12, 4407-4416. doi:10.1002/chem.200501400

13. Geyer, K.; Codée, J. D. C.; Seeberger, P. H. Chem.-Eur. J. 2006, 12, 8434-8442. doi:10.1002/chem.200600596

14. Baumann, M.; Baxendale, I. R.; Ley, S. V.; Smith, C. D.; Tranmer, G. K. Org. Lett. 2006, 8, 5231-5234. doi:10.1021/ol061975c

15. Kopach, M. E.; Roberts, D. J.; Johnson, M. D.; McClary Groh, J.; Adler, J. J.; Schafer, J. P.; Kobierski, M. E.; Trankle, W. G. Green Chem. 2012, 14, 1524-1536. doi:10.1039/c2gc35050e

16. Ruppert, J. F.; White, J. D. J. Org. Chem. 1974, 39, 269-270. doi:10.1021/j000916a043

17. Tierney, J. P.; Lidström, P., Eds. Microwave Assisted Organic Synthesis; Blackwell CRC Press: Oxford, UK, 2005. doi:10.1002/9781444305548

18. Illg, T.; Löb, P.; Hessel, V. Bioorg. Med. Chem. 2010, 18, 3707-3719. doi:10.1016/j.bmc.2010.03.073

19. Breen, J. R.; Sandford, G.; Yufit, D. S.; Howard, J. A. K.; Fray, J.; Patel, B. Beilstein J. Org. Chem. 2011, 7, 1048-1054. doi:10.3762/bjoc.7.120

20. Watts, K.; Gattrell, W.; Wirth, T. Beilstein J. Org. Chem. 2011, 7, 1108-1114. doi:10.3762/bjoc.7.127

21. Maurya, R. A.; Park, C. P.; Kim, D.-P. Beilstein J. Org. Chem. 2011, 7, 1158-1163. doi:10.3762/bjoc.7.134

22. van den Broek, S. A. M. W.; Leliveld, J. R.; Becker, R.; Delville, M. M. E.; Nieuwland, P. J.; Koch, K.; Rutjes, F. P. J. T. Org. Process Res. Dev. 2012, 16, 934-938. doi:10.1021/op2003437

23. Smith, C. J.; Smith, C. D.; Nikbin, N.; Ley, S. V.; Baxendale, I. R. Org. Biomol. Chem. 2011, 9, 1927-1937. doi:10.1039/c0ob00813c

24. Sigman, M. S.; Jacobsen, E. N. J. Am. Chem. Soc. 1998, 120, 4901-4902. doi:10.1021/ja980139y

25. Vachal, P.; Jacobsen, E. N. J. Am. Chem. Soc. 2002, 124, 10012-10014. doi:10.1021/ja027246j

26. Doyle, A. G.; Jacobsen, E. N. Chem. Rev. 2007, 107, 5713-5743. doi:10.1021/cr068373r

27. Brandsma, L.; Nedolya, N. A.; Tarasova, O. A.; Trofimov, B. A. Chem. Heterocycl. Compd. 2000, 36, 1241-1260. doi:10.1023/A:1017582315266

28. Yella, R.; Patel, B. K. J. Comb. Chem. 2010, 12, 754-763. doi:10.1021/cc100124q

29. Baxendale, I. R.; Ley, S. V.; Smith, C. D.; Tamborini, L.; Voica, A.-F. J. Comb. Chem. 2008, 10, 851-857. doi:10.1021/cc800070a

30. Ley, S. V.; Taylor, S. J. Bioorg. Med. Chem. Lett. 2002, 12, 1813-1816. doi:10.1016/S0960-894X(02)00269-X

31. Bhat, V.; Allan, K. M.; Rawal, V. H. J. Am. Chem. Soc. 2011, 133, 5798-5801. doi:10.1021/ja201834u

32. Smith, C. D.; Baxendale, I. R.; Tranmer, G. K.; Baumann, M.; Smith, S. C.; Lewthwaite, R. A.; Ley, S. V. Org. Biomol. Chem. 2007, 5, 1562-1568. doi:10.1039/b703033a
33. Drewry, D. H.; Gerritz, S. W.; Linn, J. A. Tetrahedron Lett. 1997, 38, 3377-3380. doi:10.1016/S0040-4039(97)00653-9

34. Mustafa, S. M.; Nair, V. A.; Chittoor, J. P.; Krishnapillai, S. Mini-Rev. Org. Chem. 2004, 1, 375-385. doi:10.2174/1570193043403082

35. Mukerjee, A. K.; Ashare, R. Chem. Rev. 1991, 91, 1-24. doi:10.1021/cr00001a001

36. Wong, R.; Dolman, S. J. J. Org. Chem. 2007, 72, 3969-3971. doi:10.1021/jo070246n

37. Nyoung, K. J.; Ryu, E. K. Tetrahedron Lett. 1993, 34, 8283-8284. doi:10.1016/S0040-4039(00)61411-9

38. Kim, J. N.; Jung, K. S.; Lee, H. J.; Son, J. S. Tetrahedron Lett. 1997, 38, 1597-1598. doi:10.1016/S0040-4039(97)00121-4

39. Feuer, H., Ed. Nitrile Oxides, Nitrones and Nitronates in Organic Synthesis, 2nd ed.; John Wiley \& Sons: Hoboken, New Jersey, USA, 2008.

40. Kirschning, A.; Solodenko, W.; Mennecke, K. Chem.-Eur. J. 2006, 12, 5972-5990. doi:10.1002/chem.200600236

41. Salimi, H.; Rahimi, A.; Pourjavadi, A. Monatsh. Chem. 2007, 138, 363-379. doi:10.1007/s00706-007-0616-3

42. Hodge, P. Ind. Eng. Chem. Res. 2005, 44, 8542-8553. doi:10.1021/ie040285e

43. Ley, S. V.; Baxendale, I. R. Nat. Rev. Drug Discovery 2002, 1 , 573-586. doi:10.1038/nrd871

44. Ley, S. V.; Baxendale, I. R.; Bream, R. N.; Jackson, P. S.; Leach, A. G.; Longbottom, D. A.; Nesi, M.; Scott, J. S.; Storer, R. I.; Taylor, S. J. J. Chem. Soc., Perkin Trans. 1 2000, 3815-4195. doi:10.1039/B006588I

45. Grafton, M.; Mansfield, A. C.; Fray, M. J. Tetrahedron Lett. 2010, 51, 1026-1029. doi:10.1016/j.tetlet.2009.12.071

46. Baumann, M.; Baxendale, I. R.; Ley, S. V. Synlett 2010, 749-752. doi:10.1055/s-0029-1219344

47. Brasholz, M.; Saubern, S.; Savage, G. P. Aust. J. Chem. 2011, 64, 1397-1401. doi:10.1071/CH11079

48. Castellano, S.; Tamborini, L.; Viviano, M.; Pinto, A.; Sbardella, G.; Conti, P. J. Org. Chem. 2010, 75, 7439-7442. doi:10.1021/jo1014323

49. Tran, G.; Meier, R.; Harris, L.; Browne, D. L.; Ley, S. V. J. Org. Chem. 2012, 77, 11071-11078. doi:10.1021/jo302052m

50. Harding, S. L.; Marcuccio, S. M.; Savage, G. P. Beilstein J. Org. Chem. 2012, 8, 606-612. doi:10.3762/bjoc.8.67

51. Baumann, M.; Baxendale, I. R.; Kuratli, C.; Ley, S. V.; Martin, R. E.; Schneider, J. ACS Comb. Sci. 2011, 13, 405-413. doi:10.1021/co2000357

52. Baumann, M.; Baxendale, I. R.; Kirschning, A.; Ley, S. V.; Wegner, J. Heterocycles 2011, 82, 1297-1316. doi:10.3987/COM-10-S(E)77

53. Yu, G. J.; Yang, B.; Verkman, A. S.; Kurth, M. J. Synlett 2010, 1063-1066. doi:10.1055/s-0029-1219781

54. QuadraPure ${ }^{\mathrm{TM}}$ Thiourea resin (QP-TU, loading $\sim 5.5 \mathrm{mmol} / \mathrm{g}$ ) is commercially available through Johnson-Matthey.

55. QuadraSil ${ }^{\mathrm{TM}}$ Methylthiourea (QS-MTU, loading $\sim 1.5 \mathrm{mmol} / \mathrm{g}$ ) is commercially available through Johnson-Matthey.

56. The Vapourtec R-series flow system is available from Vapourtec (http://www.vapourtec.co.uk/). 


\section{License and Terms}

This is an Open Access article under the terms of the Creative Commons Attribution License

(http://creativecommons.org/licenses/by/2.0), which permits unrestricted use, distribution, and reproduction in any medium, provided the original work is properly cited.

The license is subject to the Beilstein Journal of Organic Chemistry terms and conditions:

(http://www.beilstein-journals.org/bjoc)

The definitive version of this article is the electronic one which can be found at:

doi:10.3762/bjoc.9.184 